\title{
Local Heterozygosity Effects on Nestling Growth and Condition in the Great Cormorant
}

\author{
Piotr Minias $^{1,2} \cdot$ Katarzyna Wojczulanis-Jakubas ${ }^{3}$ Robert Rutkowski ${ }^{4}$. \\ Krzysztof Kaczmarek ${ }^{5}$
}

Received: 27 January 2015/ Accepted: 8 July 2015/Published online: 22 July 2015

(c) The Author(s) 2015. This article is published with open access at Springerlink.com

\begin{abstract}
Under inbreeding, heterozygosity at neutral genetic markers is likely to reflect genome-wide heterozygosity and, thus, is expected to correlate with fitness. There is, however, growing evidence that some of heterozygosity-fitness correlations (HFCs) can be explained by 'local effects', where noncoding loci are at linkage disequilibrium with functional genes. The aim of this study was to investigate correlations between heterozygosity at seven microsatellite loci and two fitnessrelated traits, nestling growth rate and nutritional condition, in a recently bottlenecked population of great cormorant Phalacrocorax carbo sinensis. We found that heterozygosity was positively associated with both nestling traits at the between-brood level, but the individual (within-brood) effects of heterozygosity were non-significant. We also found that only one locus per trait was primarily responsible for the significant multi-locus HFCs, suggesting a linkage disequilibrium with non-identified functional loci. The results give support for 'local effect' hypothesis, confirming that HFCs may not only be interpreted as
\end{abstract}

Piotr Minias

pminias@op.pl

1 Department of Teacher Training and Biodiversity Studies, University of Łódź, Banacha 1/3, 90-237 Łódź, Poland

2 Department of Biological Sciences, University of WisconsinMilwaukee, Milwaukee, WI 53201, USA

3 Department of Vertebrate Ecology and Zoology, University of Gdańsk, Wita Stwosza 59, 80-308 Gdańsk, Poland

4 Department of Molecular and Biometrical Techniques, Museum and Institute of Zoology PAS, 00-679 Warsaw, Poland

5 Medical University of Łódź, Sterlinga 1/3, 91-425 Łódź, Poland evidence of inbreeding and that genetic associations between functional and selectively neutral markers could be much more common in natural populations than previously thought.

Keywords Great cormorant - Growth rate . Heterozygosity-fitness correlations · Microsatellites . Phalacrocorax carbo sinensis

\section{Introduction}

Genotype-phenotype associations are often complex and difficult to disentangle, but the impact of individual genetic variation on phenotypic quality and fitness has long been recognized as an important evolutionary mechanism. Although heterozygosity has been reported to correlate with fitness-related traits such as reproductive output (Slate et al. 2000; Seddon et al. 2004; Ortego et al. 2009), survival (Markert et al. 2004; Jensen et al. 2007), parasite resistance (MacDougall-Shackleton et al. 2005; Acevedo-Whitehouse et al. 2006), competitive ability (Välimäki et al. 2007; Minias et al. 2015), developmental stability (Vangestel et al. 2011) and quality of ornamentation (Aparicio et al. 2001; Herdegen et al. 2014), the strength of the heterozygosity-fitness correlations (HFCs) is usually weak and it is still difficult to assess the generality of these associations in natural populations (Chapman et al. 2009). It is also acknowledged that HFCs may arise through several different mechanisms, but there is no clear consensus on their relative importance (Hansson and Westerberg 2002).

Heterozygosity at functional loci may affect fitness through overdominance ('direct effect' hypothesis), when heterozygous individuals have an intrinsically higher fitness than homozygotes (David 1998). This mechanism 
cannot, however, easily explain correlations between fitness and heterozygosity at noncoding markers, such as microsatellite loci. Heterozygosity at neutrally selected loci has been assumed to correlate with fitness only in inbred populations, where it is expected to reflect genome-wide heterozygosity, which in turn should correlate with individual inbreeding coefficient (Coulson et al. 1998; Slate et al. 2000). This mechanism is recognized as a 'general effect' of heterozygosity and it was initially suggested to explain a large majority of all HFCs reported for noncoding markers. This interpretation was recently challenged by studies showing a weak association between the inbreeding coefficient and heterozygosity measured across a large number of neutrally selected loci (Balloux et al. 2004; Markert et al. 2004; Slate et al. 2004). An association between heterozygosity and inbreeding was suggested to occur only when the variation in individual inbreeding coefficients within populations is high (Slate et al. 2004) or when populations are strongly substructured (Balloux et al. 2004). However, it seems that these specific conditions rarely occur in the wild and, thus, they are unlikely to explain most of the HFCs reported in empirical studies on vertebrates (Pemberton 2004).

As an alternative to the 'general effect' hypothesis, it was proposed that heterozygosity at neutral markers can have a 'local effect' on fitness, assuming that it is correlated to heterozygosity at both linked and unlinked selected loci through genetic associations (Ohta 1971; Hansson and Westerberg 2002; Szulkin et al. 2010). This hypothesis, however, requires particular population structure and specific evolutionary or ecological circumstances such as small population size, non-random mating, population admixture, or bottlenecks, which can generate nonrandom associations of alleles at different loci, known as linkage disequilibria (Brouwer et al. 2007; Szulkin et al. 2010). Although linkage disequilibria were initially considered to be restricted to a narrow chromosomal segment around the target locus, it is now realized that high levels of genome-wide linkage disequilibria may occur in natural populations (Slavov et al. 2012; Hohenlohe et al. 2012), suggesting that local heterozygosity effects could be much more widespread than previously thought. Currently, this view is gaining increasing empirical support, with local heterozygosity effects reported in many vertebrate taxa (Acevedo-Whitehouse et al. 2006; Lieutenant-Gosselin and Bernatchez 2006; Tiira et al. 2006; Charpentier et al. 2008), including several species of birds (Hansson et al. 2004; Fossøy et al. 2009; Olano-Marin et al. 2011). Taking all these into account, investigating the structure and consequences of local HFCs emerged as a new important goal of evolutionary biology, reorienting basic questions of HFC studies (Lieutenant-Gosselin and Bernatchez 2006).
The prime objective of this study was to investigate correlations between heterozygosity at seven microsatellite loci and two fitness-related traits, growth rate and nutritional condition, in great cormorant Phalacrocorax carbo sinensis nestlings from a medium-size inland colony in Poland. We expected that genome-wide inbreeding effects could be present in our population due to a severe bottleneck in the numbers of this tree-nesting subspecies $(P . c$. sinensis) that occurred throughout Europe in the middle of 20th century. By the early 1960s, the size of the entire northwestern European population was reduced to 800 pairs nesting in two Dutch colonies (Goostrey et al. 1998), whereas the Polish population was limited to only 150 pairs by the 1950s (Głowaciński 1992). In the early 1970s, the numbers of $P$. $c$. sinensis started to increase rapidly owing to a combination of relaxed human persecution, availability of new colony sites, and greatly improved food supply as the result of water eutrophication (Hagemeijer and Blair 1997), reaching over 60,000 breeding pairs in Northwest Europe by mid 1990s (Van Eerden and Gregersen 1995) and ca. 25,000 breeding pairs in Poland at the beginning of 21th century (Tomiałojć and Stawarczyk 2003). While this recent bottleneck episode could cause severe inbreeding depression across European populations, we also acknowledge that it could generate considerable linkage disequilibria, facilitating local effect of heterozygosity at neutral loci on fitness-related traits. Thus, the second aim of this study was to explore mechanisms underlying HFCs recorded within our great cormorant population, by testing whether they reflect a genome-wide general effect or a local effect of linkage disequilibrium.

\section{Methods}

\section{Study Area and General Field Procedures}

The study was conducted in the colony of great cormorants at Jeziorsko reservoir $\left(51^{\circ} 73^{\prime} \mathrm{N}, 18^{\circ} 63^{\prime} \mathrm{E}\right)$, central Poland. The colony was established in 1991, when 90 breeding pairs were recorded at the site. Since then, the size of the colony gradually increased, reaching ca. 500-600 pairs during the study period (2010-2011), and ca. 800 pairs in 2013. Although the location and spatial organization of the colony changed over time, the primary breeding habitat was the riparian willow woodland dominated by the white willow Salix alba and the grey willow Salix cinerea.

For the purpose of this study we randomly selected 57 broods at the moment of hatching ( 29 broods in 2010 and 28 broods in 2011). As HFCs can be context-dependent and their magnitude may vary with environmental conditions and along the season (Harrison et al. 2011), our sampling period spanned over the whole main hatching period in the 
colony (24 and 22 days in 2010 and 2011). In the selected broods, a minor fraction of all eggs was depredated during incubation $(3.6 \%)$ and $9.1 \%$ of eggs failed to hatch due to embryonic mortality or infertility. In all, these broods consisted of 252 eggs, 220 of which produced hatchlings sampled for molecular analysis. Blood samples for molecular analyses (ca $10 \mu \mathrm{l}$ ) were collected soon after hatching by puncturing the ulnar vein of nestlings. No brood reduction occurred before sampling. The samples were immediately suspended in $96 \%$ ethanol and stored until laboratory analyses. When hatching of the whole brood was completed, we collected the following measurements from all the hatchlings: body mass $( \pm 1 \mathrm{~g})$, wing length $( \pm 1 \mathrm{~mm})$, culmen and tarsus length (both $\pm 0.1 \mathrm{~mm})$. Since great cormorants lay eggs in 1-3 day intervals (clutch size of 3-6 eggs) and start incubating from the first egg, the hatching is asynchronous and broods typically contain chicks of different sizes. To determine hatching order, all measurements collected after hatching were reduced to the first principal component (PC1) of the principal component analysis (PCA). PC1 accounted for $96.1 \%$ of the variability in all chosen variables and all body measurements had similar contributions to PC1 (from 0.251 to 0.256 ). Hatching ranks were established based on size ranks assigned to each chick from PC1 values, which followed methodology used in other species of waterbirds that exhibit marked hatching asynchrony (e.g., Cash and Evans 1986), including several cormorant species (Shaw 1985; Stockland and Amundsen 1988). All chicks were tagged on the tarsus with flexible Velcro ${ }^{\mathrm{TM}}$ strips of different colours. These strips were enlarged according to the size of chicks during successive visits. At the age of 13 days all chicks were marked with individually-numbered metal rings and Velcro ${ }^{\mathrm{TM}}$ strips were removed.

\section{Nestling Growth Rate}

Body mass of nestlings was repeatedly measured over the period of 22 days with 3- to 5-day intervals, resulting in at least five measurements per chick. It was not possible to collect measurements near fledging, as chicks older than 25 days may jump out of the nests if humans approach (Platteeuw et al. 1995; pers. observ.). To calculate nestling growth rates we fitted logistic curves of the form $y=A$ / $[1+\mathrm{B} \times \exp (-\mathrm{KT})]$ to the measurements of body mass, where $y$ refers to the body measurement at age $\mathrm{T}, \mathrm{A}$ is an asymptotic value, $\mathrm{B}$ is a constant of integration, and $\mathrm{K}$ is the growth rate constant. We used parameter $\mathrm{K}$ from the fitted curves as an indicator of chick growth rates. Since we stopped collecting measurements when nestlings had not yet reached asymptotic values of their body mass, the parameter $\mathrm{A}$ of the curve equation was constrained with the expected mean fledgling body mass of male (2379 $\mathrm{g}$ ) or female (1946 g) great cormorant chicks (Liordos and Goutner 2008).

\section{Nestling Nutritional Condition}

When the oldest chick in the nest was $22 \pm 1$ days old, we collected approximately $2 \mathrm{ml}$ of blood from ulnar vein of each chick for biochemical analyses. Due to high chick mortality [mainly due to nest collapse and starvation, see Minias and Kaczmarek (2013a) for details], we collected blood samples for 157 chicks. Blood samples were placed in tubes of EDTA, kept in a cooler, and centrifuged at 3000 r.p.m. for $15 \mathrm{~min}$ within $8 \mathrm{~h}$ of collection. The plasma was separated and kept at $-20{ }^{\circ} \mathrm{C}$ until analyses. Concentrations of the following plasma metabolites were analysed for all chicks with a spectrophotometer (BTS-330, BioSystems Reagents \& Instruments, Barcelona, Spain) using the methods and wavelengths given in parentheses: albumin (bromocresol green, $630 \mathrm{~nm}$ ), triglycerides (glycerol phosphate oxidase/peroxidase, $500 \mathrm{~nm}$ ), uric acid (uricase/peroxidase, $520 \mathrm{~nm}$ ). All parameters were analysed using commercial kits and reagents (BioSystems Reagents \& Instruments, Barcelona, Spain). $10 \mu \mathrm{l}$ of plasma was used for albumin and triglyceride measurements, while uric acid was measured in $25 \mu$ of plasma volume, following manufacturer protocols. Repeatabilities (Lessells and Boag 1987) of measurements were high or very high (albumin: repeatability $=0.84, \mathrm{~F}_{60,59}=20.62$, $p<0.001$; triglycerides: repeatability $=0.97, \mathrm{~F}_{60,59}=$ $65.10, p<0.001$; uric acid: repeatability $=0.97, \mathrm{~F}_{60,59}=$ $87.87, p<0.001$ ), based on duplicate assays for 30 randomly selected chicks.

Plasma concentrations of triglycerides and uric acid positively correlated with body mass-tarsus residuals (triglycerides: $\mathrm{r}=0.28, p<0.001$; uric acid: $\mathrm{r}=0.29$, $p<0.001)$ and a similar correlation for albumin concentration was marginally significant $(\mathrm{r}=0.15, p=0.063)$, indicating that these parameters were likely to reliably indicate nutritional condition of cormorant nestlings. Since all three parameters were inter-correlated (all $p<0.001$, except for the correlation between albumin and uric acid where $p=0.17$ ), we reduced them to the first principal component (PC1) using PCA. The analysis was done on log-transformed data using a correlation matrix with no factor rotation. PC1 accounted for $59.1 \%$ of variability in all univariate measurements (eigenvalue 1.77). Factor loadings were 0.73 for albumin, 0.89 for triglycerides, and 0.66 for uric acid. PC1 scores were log-transformed to improve normality, standardized to equal-unit variances ( $\mathrm{z}$ scores) and used as a proxy of nestling nutritional condition. 


\section{Molecular Analyses}

We performed molecular sexing and microsatellite genotyping on DNA extracted from the blood after evaporation of the alcohol (Blood Mini kit, A\&A Biotechnology, Gdynia, Poland). For molecular sexing, we amplified the chromohelicase-DNA binding protein (CHD) gene with the primer pair 2550F and 2718R (Fridolfsson and Ellegren 1999), according to the protocol described by Griffiths et al. (1998). PCR products (ca. 200 bp) were separated by electrophoresis in a $2 \%$ agarose gel stained with ethidium bromide until the differences in size were clearly visible in UV light.

For genotyping, we used seven microsatellite loci previously developed for the great cormorant (Piertney et al. 1998). Forward primers were labelled with fluorescent dye (D2, D3, D4, Sigma-Aldrich, Poland). We used multiplex procedure for five loci (PcD4, PcD6, PcT1, PcT3, PcT4) using multiplex PCR Kit (Qiagen) in 15 ul total volume, and a separate PCR for the two other loci (PcD2, PcD5) using Polimerease mix (Sigma Aldrich) in $25 \mu \mathrm{l}$ total volume. We used a $55^{\circ} \mathrm{C}$ annealing temperature for both types of reactions. We genotyped the PCR products using a Beckman Coulter CEQ 8000 capillary automated sequencer at the Museum and Institute of Zoology, Polish Academy of Science (Warsaw, Poland). We scored alleles visually using the Beckman Coulter Fragment Analysis Software. 20 samples $(9.1 \%, \mathrm{n}=220)$ failed to amplify at one or more loci and were excluded from the data set.

\section{Microsatellite Markers and Heterozygosity}

The mean number of alleles per locus was 27.3 (9-51 alleles) and observed heterozygosity ranged from 0.61 to 0.96 (Table 1). We could not directly test for linkage disequilibrium between the loci in our population due to high relatedness between individuals within broods and unknown relatedness between broods sampled in different years (due to possible shared parentage). However, as

Table 1 Characterization of seven polymorphic loci used in this study with number of alleles $\left(\mathrm{N}_{\mathrm{A}}\right)$, allele size range, expected heterozygosity $\left(\mathrm{H}_{\mathrm{e}}\right)$, observed heterozygosity $\left(\mathrm{H}_{\mathrm{o}}\right)$

\begin{tabular}{lrlll}
\hline Locus & $\mathrm{N}_{\mathrm{A}}$ & Size range (bp) & $\mathrm{H}_{\mathrm{e}}$ & $\mathrm{H}_{\mathrm{o}}$ \\
\hline PcD2 & 11 & $168-212$ & 0.85 & 0.83 \\
PcD4 & 13 & $150-180$ & 0.82 & 0.81 \\
PcD5 & 17 & $204-262$ & 0.82 & 0.82 \\
PcD6 & 9 & $170-192$ & 0.61 & 0.61 \\
PcT1 & 49 & $287-437$ & 0.96 & 0.96 \\
PcT3 & 51 & $214-354$ & 0.97 & 0.94 \\
PcT4 & 41 & $183-295$ & 0.95 & 0.91 \\
\hline
\end{tabular}

indicated by the genotypic analysis of great cormorants from over 20 European colonies, there was no indication of linkage disequilibrium between the loci and no consistent deviations from Hardy-Weinberg equilibrium (Goostrey et al. 1998). To estimate individual genetic diversity we calculated homozygosity by locus which weights the contribution of each locus to the homozygosity value depending on the allelic variability (Aparicio et al. 2006). As indicated by simulations, homozygosity by locus can outperform other metrics of heterozygosity, such as internal relatedness (IR, Amos et al. 2001), especially at loci with high allelic diversity (Aparicio et al. 2006). Homozygosity by locus was calculated as $\mathrm{HL}=\left(\Sigma E_{h}\right) /$ $\left(\Sigma E_{h}+\Sigma E_{j}\right)$, where $E_{h}$ and $E_{j}$ are the expected heterozygosities of the loci that an individual bears in homozygosis $(h)$ and in heterozygosis $(j)$, respectively (Aparicio et al. 2006). In all the analyses we used $1-\mathrm{HL}$, so that higher values indicate higher heterozygosity.

\section{HFC Calculations}

To analyse the effects of heterozygosity on nestling growth rate and nutritional condition we used general linear mixed models (GLMM) with nest identity included as random factor to avoid pseudoreplication (Hurlbert 1984). Since marked competitive hierarchies that arise within great cormorant broods due to hatching asynchrony are known to be a key determinant of chick growth and condition (Minias and Kaczmarek 2013b), we expected that the effects of heterozygosity may be apparent only at the between-nest level. Thus, to separate within- and betweennest effects of heterozygosity we used within-group centering, where the centered value (representing a within-nest effect) and the mean value of each nest (representing a between-nest effect) was included in the same model (van de Pol and Wright 2009). Hatching rank, hatching date and brood size were included as covariate factors in each model. Since great cormorants are sexually dimorphic in size, with males on average $10 \%$ larger than females (Koffijberg and Van Eerden 1995), we entered nestling sex as a fixed factor in the models to account for inter-sexual variation in growth and condition. We also controlled for between-year variation in all the models. We used a stepwise procedures of backward removal to select for significant independent variables. Marginally significant effects $(p<0.06)$ were retained in the reduced models. All GLMMs were analysed with JMP Pro 10 (SAS Institute Inc., Cary, NC, USA).

\section{Identity Disequilibrium}

General effects of heterozygosity are expected to occur only when the variance in individual inbreeding 
coefficients within population is large enough to cause identity disequilibrium, which is a correlation of heterozygosity or homozygosity across markers within individuals and which should reflect identity by descent (IBD) of those markers (Bierne et al. 2000; Szulkin et al. 2010; Miller and Coltman 2014). We tested for identity disequilibrium with two approaches. First, we calculated heterozygosity-heterozygosity correlation (HHC) according to the procedure described by Balloux et al. (2004). All the markers were randomly divided into two subsets of three and four loci that were separately used to calculate multi-locus heterozygosity and then the correlation coefficient between the heterozygosity of the two subsets was calculated. Significance of HHC was tested with 1000 random partitions of loci in $\mathrm{R}$ ( $\mathrm{R}$ Development Core Team 2013) using the ' $h$ _cor' function in the 'Rhh' package (Alho et al. 2010). However, this procedure was suggested to yield a complicated distribution of HHC coefficients, which are not independent from one another and, consequently, cannot provide any synthetic measure related to HFC theory (Szulkin et al. 2010). Thus, we also calculated the $\mathrm{g}_{2}$ statistic developed by David et al. (2007), which assesses the covariance of heterozygosity between markers standardized by their average heterozygosity. As such, $\mathrm{g}_{2}$ summarizes the variance in inbreeding within population, rather than individual realized IBD (Szulkin et al. 2010; Miller and Coltman 2014). $\mathrm{g}_{2}$ was calculated using RMES software (David et al. 2007) and its significance was tested with 1000 genotype permutations.

\section{Results}

After accounting for the effects of sex, hatching rank, and year, we found a significant positive relationship between multi-locus heterozygosity and nestling growth rate at the between-nest level (Fig. 1a), while there was no significant within-nest relationship between these traits (Table 2). A similar pattern was found for nutritional condition of nestlings, with multi-locus heterozygosity showing a significant between-nest effect (Fig. 1b) and no significant within-nest effect of heterozygosity on condition (Table 3).

To test whether the HFC recorded at the between-nest level for each of fitness-related traits can be explained with the local effect hypothesis we compared a model incorporating specific heterozygosity effects separately for each locus $(m 2)$ with a model of multi-locus heterozygosity calculated across all loci $(\mathrm{ml}$, following Szulkin et al. 2010). While we failed to find any significant difference in the variance explained by both models for nestling growth rate $\left(\mathrm{F}_{6,149}=0.87, p=0.52\right)$, there was a strong support for a local effect of heterozygosity acting on chick nutritional condition, as the model with single-locus effects


Fig. 1 Between-nest effects (mean values for each nest) of multilocus heterozygosity on growth rate (a) and nutritional condition (b) of great cormorant nestlings. The lines indicate fitted regressions

explained significantly more variance than the model with heterozygosity at multiple loci $\left(\mathrm{F}_{6,149}=4.49, p<0.001\right)$. As indicated by the model with single-locus effects, only one of the markers (PcD2) showed significant positive association with nestling nutritional condition and, thus, appeared to contribute disproportionately toward the observed HFC (Table 4; Fig. 2b). In fact, after removing PcD2 from the estimate of multi-locus heterozygosity, the relationship between heterozygosity and nestling nutritional condition was no longer significant $\left(\mathrm{F}_{1,104}=0.22\right.$, $p=0.64)$. Similarly, only one marker $(\mathrm{PcD} 4)$ revealed a nearly significant positive association with nestling growth rate (Table 4; Fig. 2a) and multi-locus heterozygosity calculated for all other marker was not significantly related to nestling growth rate $\left(\mathrm{F}_{1,102}=1.59, p=0.21\right)$.

We found no evidence for significant identity disequilibrium in our dataset. The mean within-individual HHC coefficient calculated according to Balloux et al. (2004) was negative and did not differ significantly from zero 
Table 2 Mixed model analyses showing within- and between-nest effects of heterozygosity on growth rates of great cormorant nestlings $(\mathrm{n}=157)$

\begin{tabular}{lrrl}
\hline Factor & Estimate $\pm \mathrm{SE}$ & \multicolumn{1}{l}{$t$} & \multicolumn{1}{l}{$p$} \\
\hline Full model & & & \\
Intercept & $0.076 \pm 0.054$ & 1.41 & 0.17 \\
Within-nest heterozygosity & $0.016 \pm 0.020$ & 0.80 & 0.42 \\
Between-nest heterozygosity & $0.162 \pm 0.053$ & 3.05 & 0.004 \\
Sex & $0.006 \pm 0.002$ & 2.54 & 0.012 \\
Brood size & $0.006 \pm 0.006$ & 1.14 & 0.26 \\
Hatching rank & $-0.004 \pm 0.002$ & -2.19 & 0.031 \\
Hatching date & $0.004 \pm 0.004$ & 1.11 & 0.27 \\
Year & $-0.010 \pm 0.004$ & -2.70 & 0.010 \\
Reduced model & & & \\
Intercept & $0.135 \pm 0.046$ & 2.97 & 0.005 \\
Between-nest heterozygosity & $0.114 \pm 0.053$ & 2.15 & 0.036 \\
Hatching rank & $-0.004 \pm 0.002$ & -1.91 & 0.058 \\
Sex & $0.006 \pm 0.002$ & 2.64 & 0.010 \\
Year & $-0.009 \pm 0.004$ & -2.39 & 0.021 \\
\hline
\end{tabular}

The results of full model and reduced model are presented. Brood identity was included as a random factor to control for non-independence among young within a brood

Table 3 Mixed model analyses showing within- and between-nest effects of heterozygosity on nutritional condition of great cormorant nestlings $(\mathrm{n}=157)$

\begin{tabular}{lrrr}
\hline Factor & Estimate $\pm \mathrm{SE}$ & \multicolumn{1}{l}{$t$} & \multicolumn{1}{l}{$p$} \\
\hline Full model & & & \\
Intercept & $-1.97 \pm 1.39$ & -1.42 & 0.16 \\
Within-nest heterozygosity & $0.82 \pm 0.80$ & 1.03 & 0.31 \\
Between-nest heterozygosity & $2.05 \pm 1.36$ & 1.51 & 0.14 \\
Sex & $0.00 \pm 0.08$ & 0.01 & 0.99 \\
Brood size & $0.08 \pm 0.14$ & 0.53 & 0.60 \\
Hatching rank & $-0.02 \pm 0.08$ & -0.32 & 0.75 \\
Hatching date & $0.12 \pm 0.10$ & 1.23 & 0.23 \\
Year & $-0.17 \pm 0.09$ & -1.76 & 0.09 \\
Reduced model & & & \\
Intercept & $-2.18 \pm 1.09$ & -2.00 & 0.051 \\
Between-nest heterozygosity & $2.57 \pm 1.28$ & 2.01 & 0.049 \\
\hline
\end{tabular}

The results of full model and reduced model are presented. Brood identity was included as a random factor to control for non-independence among young within a brood

( $\mathrm{r}=-0.06,95 \% \mathrm{CI}=-0.15$ to 0.01$)$. Consistently, the $\mathrm{g}_{2}$ statistic did not significantly differ from zero $\left(\mathrm{g}_{2}=-0.0023, p=0.78\right)$, suggesting that heterozygosity measured at our set of microsatellite loci may not be representative of inbreeding.
Table 4 Between-nest effects of single-locus heterozygosity on growth rate and nutritional condition of great cormorant nestlings

\begin{tabular}{llllcc}
\hline Locus & \multicolumn{2}{l}{ Growth rate } & & & \multicolumn{2}{l}{ Nutritional condition } \\
\cline { 2 - 3 } \cline { 6 - 6 } & Estimate $\pm \mathrm{SE}$ & $p$ & & Estimate $\pm \mathrm{SE}$ & \multicolumn{1}{c}{$p$} \\
\hline PcD2 & $0.008 \pm 0.065$ & 0.67 & & $\mathbf{1 . 5 9} \pm \mathbf{0 . 3 4}$ & $<\mathbf{0 . 0 0 1}$ \\
PcD4 & $\mathbf{0 . 0 3 5} \pm \mathbf{0 . 0 1 8}$ & $\mathbf{0 . 0 5 7}$ & & $-0.17 \pm 0.34$ & 0.61 \\
PcD5 & $0.004 \pm 0.015$ & 0.78 & & $0.20 \pm 0.29$ & 0.49 \\
PcD6 & $0.012 \pm 0.013$ & 0.35 & & $-0.02 \pm 0.24$ & 0.93 \\
PcT1 & $0.065 \pm 0.038$ & 0.11 & & $0.50 \pm 0.75$ & 0.49 \\
PcT3 & $0.011 \pm 0.028$ & 0.70 & & $-0.01 \pm 0.53$ & 0.99 \\
PcT4 & $0.021 \pm 0.030$ & 0.50 & & $-0.14 \pm 0.58$ & 0.81 \\
\hline
\end{tabular}

Significant and marginally significant $(p<0.06)$ values are in bold


Fig. 2 Between-nest effects (mean values for each nest) of single locus heterozygosity on growth rate (a) and nutritional condition (b) of great cormorant nestlings. The lines indicate fitted regressions

\section{Discussion}

We demonstrated that heterozygosity at neutral markers was positively correlated with growth and condition of great cormorant nestlings, but we also found that these 
relationships were primarily driven by heterozygosity at single loci. Model comparisons according to the procedure proposed by Szulkin et al. (2010) gave strong support for the local effect of heterozygosity acting on nestling nutritional condition only, but it must be kept in mind that the local effects are extremely difficult to detect with this methodology if the multi-locus heterozygosity effects are already weak (Szulkin et al. 2010). In fact, Szulkin et al. (2010) were not aware of any HFC data that passed this rigorous test and detected significant local effects. Taking all this into account, our results provide empirical evidence for the local heterozygosity effects on at least one fitnessrelated trait in great cormorant nestlings. Consequently, it seems likely that the loci contributing most to the observed HFCs could be at linkage disequilibrium with genes under selection, presumably with ones that play a part in regulation of growth or metabolic pathways. Such linkage disequilibria may arise in finite populations as a result of genetic drift, especially following recent bottlenecks or colonisation of new areas (Szulkin et al. 2010). In fact, we expected that the recent dramatic reduction in the size of the European $P$. c. sinensis population could have generated extensive linkage disequilibria across the genome. We found no correlation between heterozygosity at individual microsatellite loci, suggesting that our estimate of multilocus heterozygosity did not reflect genome-wide heterozygosity, thus not supporting the 'general effect' hypothesis. Also, the parameter $g_{2}$ gave no indication for inbreeding in our population. The results confirm that HFCs, at least those derived from studies examining very small number of loci, may not only be interpreted as evidence of inbreeding and that genetic associations between functional and selectively neutral markers could be much more common in natural populations than previously thought.

In this study, local effects of heterozygosity were found only at the between-brood level with no individual effects apparent within broods. This pattern was expected in the great cormorant, because the pronounced hatching asynchrony of nestlings (hatching period lasting up to 5 days in large broods) results in marked competitive asymmetries within broods. Great cormorant nestlings that hatch later in the hatching sequence have lower access to food delivered by parents, which leads to significant reductions in body mass and slower growth rates in comparison to older siblings. In our population, a large proportion of variation in chick body mass $(81 \%)$ and concentration of plasma metabolites (68-76\%) was attributed to within-brood differences (Minias and Kaczmarek 2013b). Consequently, it seems that within-brood effects of heterozygosity could be masked by very strong effects of competitive hierarchies among young. Taking this into account, we suggest that within-brood effects of heterozygosity are much more likely to be found in species where offspring hatch synchronously. Consistent with this prediction, there is empirical evidence for within-brood effects of heterozygosity on such fitness-related traits as survival (Hansson et al. 2001; Townsend and Jamieson 2013) or cell-mediated immunity (Fossøy et al. 2009; Voegeli et al. 2013) in synchronously or nearly-synchronously hatching passerines. Although both general and local effects were suggested to underlie these relationships, it has been recently pointed out that within-brood HFCs should be interpreted with care, as full-siblings can vary in the proportion of the genome that is identical by descent due to chance events during Mendelian segregation, and such variation may be sufficient to cause HFCs among full-sibs (Forstmeier et al. 2012). Interpretation of within-brood HFCs may also be hampered by the effects of mixed paternity (Townsend and Jamieson 2013). While there is a molecular evidence for extra-pair paternity (EPP) in the Great Cormorant, its frequency was reported to vary substantially between colonies (Piertney et al. 2003) and no information on the level of EPP was available for our studied population.

We cannot exclude the possibility that there was also an indirect effect of parental genetic quality contributing to the HFCs found in this cormorant population. Genetic diversity is theoretically expected to be correlated between parents and offspring, since at most allelic frequencies heterozygous parents produce higher proportions of heterozygous progeny than homozygous parents (Mitton et al. 1993). Positive associations between parental and offspring heterozygosity were empirically demonstrated for birds (García-Navas et al. 2009) and other vertebrate species (Cothran et al. 1983; Hoffman et al. 2007). Thus, fitness benefits associated with genetic diversity can be partly heritable, but the effect of parental heterozygosity on nestling development may also have a non-genetic component. Heterozygous parents may have increased competitive abilities (Höglund et al. 2002; Minias et al. 2015), which, in turn, can increase their foraging efficiency and elevate the amount of food delivered to offspring, thus having a positive impact on their growth and condition. Alternatively, adults paired with genetically dissimilar mates may increase their parental investment in offspring, which can amplify complementary gene effects and drive enhanced nestling growth rates or condition (Potvin and MacDougall-Shackleton 2009; Arct et al. 2010). As a consequence, studies with an appropriate experimental design would be necessary to explicitly separate non-genetic parental effect from genetic effects of heterozygosity on fitness-related traits of their progeny.

Acknowledgments The study was performed under the permissions of the Bioethical Commission and the Regional Environmental Protection Directorate in Łódź, Poland. The study was supported by the 
Grants from the University of Gdańsk (BW/L120-5-0422-0) and from the Ministry of Science and Higher Education in Poland (NN303 319940). We are very grateful to Tomasz Janiszewski, Bartosz Lesner, Anna Piasecka and Radosław Włodarczyk for their help with the fieldwork. We also appreciate helpful comments on the earlier draft of the manuscript by Nicola Nadeau, Linda Whittingham, Peter Dunn, and two anonymous reviewers.

Open Access This article is distributed under the terms of the Creative Commons Attribution 4.0 International License (http://crea tivecommons.org/licenses/by/4.0/), which permits unrestricted use, distribution, and reproduction in any medium, provided you give appropriate credit to the original author(s) and the source, provide a link to the Creative Commons license, and indicate if changes were made.

\section{References}

Acevedo-Whitehouse, K., Spraker, T. R., Lyons, E., Melin, S. R., Gulland, F., Delong, R. L., \& Amos, W. (2006). Contrasting effects of heterozygosity on survival and hookworm resistance in California sea lion pups. Molecular Ecology, 15, 1973-1982.

Alho, J. S., Välimäki, K., \& Merilä, J. (2010). Rhh: An R extension for estimating multilocus heterozygosity and heterozygosityheterozygosity correlation. Molecular Ecology Resources, 10, $720-722$.

Amos, W., Wilmer, J. W., Fullard, K., Burg, T. M., Croxall, J. P., Bloch, D., \& Coulson, T. (2001). The influence of parental relatedness on reproductive success. Proceeding of the Royal Society B, 268, 2021-2027.

Aparicio, J. M., Cordero, P. J., \& Veiga, J. P. (2001). A test of the hypothesis of mate choice based on heterozygosity in the spotless starling. Animal Behaviour, 62, 1001-1006.

Aparicio, J. M., Ortego, J., \& Cordero, P. J. (2006). What should we weigh to estimate heterozygosity, alleles or loci? Molecular Ecology, 15, 4659-4665.

Arct, A., Rutkowska, J., Martyka, R., Drobniak, S. M., \& Cichoń, M. (2010). Kin recognition and adjustment of reproductive effort in zebra finches. Biology Letters, 6, 762-764.

Balloux, F., Amos, W., \& Coulson, T. (2004). Does heterozygosity estimate inbreeding in real populations? Molecular Ecology, 13, 3021-3031.

Bierne, N., Tsitrone, A., \& David, P. (2000). An inbreeding model of associative overdominance during a population bottleneck. Genetics, 155, 1981-1990.

Brouwer, L., Komdeur, J., \& Richardson, D. S. (2007). Heterozygosity-fitness correlations in a bottlenecked island species: A case study on the Seychelles warbler. Molecular Ecology, 16, 3134-3144.

Cash, K. J., \& Evans, R. M. (1986). Brood reduction in the American Pelican (Pelecanus erythrorhynchos). Behavioral Ecology and Sociobiology, 18, 413-418.

Chapman, J. R., Nakagawa, S., Coltman, D. W., Slate, J., \& Sheldon, B. C. (2009). A quantitative review of heterozygosity-fitness correlations in animal populations. Molecular Ecology, 18, 2746-2765.

Charpentier, M. J., Prugnolle, F., Gimenez, O., \& Widdig, A. (2008). Genetic heterozygosity and sociality in a primate species. Behavior Genetics, 38, 151-158.

Cothran, E. G., Chesser, R., Smith, M. H., \& Johns, P. E. (1983). Influences of genetic variability and maternal factors on fetal growth in white-tailed deer. Evolution, 37, 282-291.

Coulson, T. N., Pemberton, J. M., Albon, S. D., Beaumont, M. A., Marshall, T. C., Slate, J., et al. (1998). Microsatellites reveal heterosis in red deer. Proceedings of the Royal Society B, 265, 489-495.

David, P. (1998). Heterozygosity-fitness correlations: New perspective on old problems. Heredity, 80, 531-537.

David, P., Pujol, B., Viard, F., Castella, V., \& Goudet, J. (2007). Reliable selfing rate estimates from imperfect population genetic data. Molecular Ecology, 16, 2474-2487.

Forstmeier, W., Schielzeth, H., Mueller, J. C., Ellegren, H., \& Kempenaers, B. (2012). Heterozygosity-fitness correlations in zebra finches: Microsatellite markers can be better than their reputation. Molecular Ecology, 21, 3237-3249.

Fossøy, F., Johnsen, A., \& Lifjeld, J. T. (2009). Cell-mediated immunity and multi-locus heterozygosity in bluethroat nestlings. Journal of Evolutionary Biology, 22, 1954-1960.

Fridolfsson, A. K., \& Ellegren, H. (1999). A simple and universal method for molecular sexing of non ratite birds. Journal of Avian Biology, 30, 116-121.

García-Navas, V., Ortego, J., \& Sanz, J. J. (2009). Heterozygositybased assortative mating in blue tits (Cyanistes caeruleus): Implications for the evolution of mate choice. Proceedings of the Royal Society B, 276, 2931-2940.

Głowaciński, Z. (Ed.). (1992). Polish red data book of animals, Vertebrates. Warszawa: PWRiL. (in Polish with English summary).

Goostrey, A., Carss, D. N., Noble, L. R., \& Piertney, S. B. (1998). Population introgression and differentiation in the great cormorant Phalacrocorax carbo in Europe. Molecular Ecology, 7, 329-338.

Griffiths, R., Double, M. C., Orr, K., \& Dawson, R. J. (1998). A DNA test to sex most birds. Molecular Ecology, 7, 1071-1075.

Hagemeijer, W. J. M., \& Blair, M. J. (1997). The EBCC atlas of European breeding birds: Their distribution and abundance. London: Poyser.

Hansson, B., Bensch, S., Hasselquist, D., \& Åkesson, M. (2001). Microsatellite diversity predicts recruitment of sibling great reed warblers. Proceedings of the Royal Society B, 268, 1287-1291.

Hansson, B., \& Westerberg, L. (2002). On the correlation between heterozygosity and fitness in natural populations. Molecular Ecology, 11, 2467-2474.

Hansson, B., Westerdahl, H., Hasselquist, D., Åkesson, M., \& Bensch, S. (2004). Does linkage disequilibrium generate heterozygosity-fitness correlations in great reed warblers? Evolution, 58, 870-879.

Harrison, X. A., Bearhop, S., Inger, R., Colhoun, K., Gudmundsson, G. A., Hodgson, D., et al. (2011). Heterozygosity-fitness correlations in a migratory bird: An analysis of inbreeding and single-locus effects. Molecular Ecology, 20, 4786-4795.

Herdegen, M., Dudka, K., \& Radwan, J. (2014). Heterozygosity and orange coloration are associated in the guppy (Poecilia reticulata). Journal of Evolutionary Biology, 27, 220-225.

Hoffman, J. I., Forcada, J., Trathan, P. N., \& Amos, W. (2007). Female fur seals show active choice for males that are heterozygous and unrelated. Nature, 445, 912-914.

Höglund, J., Piertney, S. B., Alatalo, R. V., Lindell, J., Lundberg, A., \& Rintamäki, P. T. (2002). Inbreeding depression and male fitness in black grouse. Proceedings of the Royal Society B, 269, 711-715.

Hohenlohe, P. A., Bassham, S., Currey, M., \& Cresko, W. A. (2012). Extensive linkage disequilibrium and parallel adaptive divergence across threespine stickleback genomes. Philosophical Transactions of the Royal Society B, 367, 395-408.

Hurlbert, S. H. (1984). Pseudoreplication and the design of the ecological field experiments. Ecological Monographs, 54, 187-211.

Jensen, H., Bremset, E. M., Ringsby, T. H., \& Sæther, B.-E. (2007). Multilocus heterozygosity and inbreeding depression in an 
insular house sparrow metapopulation. Molecular Ecology, 16, 4066-4078.

Koffijberg, K., \& Van Eerden, M. R. (1995). Sexual dimorphism in the Cormorant Phalacrocorax carbo sinensis: Possible implications for differences in structural size. Ardea, 83, 37-46.

Lessells, C. M., \& Boag, P. T. (1987). Unrepeatable repeatabilities: A common mistake. The Auk, 104, 116-121.

Lieutenant-Gosselin, M., \& Bernatchez, L. (2006). Local heterozygosity-fitness correlations with global positive effects on fitness in threespine stickleback. Evolution, 60, 1658-1668.

Liordos, V., \& Goutner, V. (2008). Sex determination of Great Cormorants (Phalacrocorax carbo sinensis) using morphometric measurements. Waterbirds, 31, 203-210.

MacDougall-Shackleton, E. A., Derryberry, E. P., Foufopoulos, J., Dobson, A. P., \& Hahn, T. P. (2005). Parasite-mediated heterozygote advantage in an outbred songbird population. Biology Letters, 1, 105-107.

Markert, J. A., Grant, P. R., Keller, L. F., Coombs, J. L., \& Petren, K. (2004). Neutral locus heterozygosity, inbreeding, and survival in Darwin's ground finches (Geospiza fortis and G. scandens). Heredity, 92, 306-315.

Miller, J. M., \& Coltman, D. W. (2014). Assessment of identity disequilibrium and its relation to empirical heterozygosity fitness correlations: A meta-analysis. Molecular Ecology, 23, 1899-1909.

Minias, P., \& Kaczmarek, K. (2013a). Is it always beneficial to breed in the centre? Trade-offs in nest site selection within the colony of a tree-nesting waterbird. Journal of Ornithology, 154, 945-953.

Minias, P., \& Kaczmarek, K. (2013b). Concentrations of plasma metabolites as predictors of nestling condition in the Great Cormorant (Phalacrocorax carbo sinensis). Ornis Fennica, 90, $142-150$

Minias, P., Minias, A., \& Dziadek, J. (2015). Heterozygosity correlates with body size, nest site quality and productivity in a colonial waterbird, the whiskered tern (Chlidonias hybrida, Aves: Sternidae). Journal of Zoological Systematics and Evolutionary Research, 53, 133-139.

Mitton, J. B., Schuster, W. S. F., Cothran, E. G., \& Defries, J. C. (1993). Correlation between the individual heterozygosity of parents and their offspring. Heredity, 71, 59-63.

Ohta, T. (1971). Associative overdominance caused by linked detrimental mutations. Genetical Research, 18, 277-286.

Olano-Marin, J., Mueller, J. C., \& Kempenaers, B. (2011). Heterozygosity and survival in blue tits (Cyanistes caeruleus): Contrasting effects of presumably functional and neutral loci. Molecular Ecology, 20, 4028-4041.

Ortego, J., Calabuig, G., Bonal, R., Muñoz, A., Aparicio, J. M., \& Cordero, P. J. (2009). Temporal variation of heterozygositybased assortative mating and related benefits in a lesser kestrel population. Journal of Evolutionary Biology, 22, 2488-2495.

Pemberton, J. (2004). Measuring inbreeding depression in the wild: The old ways are the best. Trends in Ecology \& Evolution, 19, 613-615.

Piertney, S. B., Carss, D. N., \& Goostrey, A. (2003). Population variation in the frequency of extra-pair paternity in the great cormorant Phalacrocorax carbo. Vogelwelt, 124(Suppl), $149-155$

Piertney, S. B., Goostrey, A., Dallas, J. F., \& Carss, D. N. (1998). Highly polymorphic microsatellite markers in the great cormorant Phalacrocorax carbo. Molecular Ecology, 7, 138-140.

Platteeuw, M., Koffijberg, K., \& Dubbeldam, W. (1995). Growth of Cormorant Phalacrocorax carbo sinensis chicks in relation to brood size, age ranking and parental fishing effort. Ardea, 83, 235-245.

Potvin, D. A., \& MacDougall-Shackleton, E. A. (2009). Parental investment amplifies effects of genetic complementarity on growth rates in song sparrows, Melospiza melodia. Animal Behaviour, 78, 943-948.

R Development Core Team. (2013). R: A language and environment for statistical computing. R Foundation for Statistical Computing, Vienna, Austria. ISBN 3-900051-07-0. http://www.Rproject.org/

Seddon, N., Amos, W., Mulder, R. A., \& Tobias, J. A. (2004). Male heterozygosity predicts territory size, song structure and reproductive success in a cooperatively breeding bird. Proceedings of the Royal Society B, 271, 1823-1829.

Shaw, P. (1985). Brood reduction in the Blue-eyed Shag Phalacrocorax atriceps. Ibis, 127, 476-494.

Slate, J., David, P., Dodds, K. G., Veenvliet, B. A., Glass, B. C., Broad, T. E., \& McEwan, J. C. (2004). Understanding the relationship between the inbreeding coefficient and multilocus heterozygosity: Theoretical expectations and empirical data. Heredity, 93, 255-265.

Slate, J., Kruuk, L. E. B., Marshall, T. C., Pemberton, J. M., \& Clutton-Brock, T. H. (2000). Inbreeding depression influences lifetime reproductive success in a wild population of red deer (Cervus elaphus). Proceedings of the Royal Society B, 267, 1657-1662.

Slavov, G. T., DiFazio, S. P., Martin, J., Schackwitz, W., Muchero, W., Rodgers-Melnick, E., et al. (2012). Genome resequencing reveals multiscale geographic structure and extensive linkage disequilibrium in the forest tree Populus trichocarpa. New Phytologist, 196, 713-725.

Stockland, J. N., \& Amundsen, T. (1988). Initial size hierarchy in broods of the Shag: Relative significance of egg size and hatching asynchrony. The Auk, 105, 308-315.

Szulkin, M., Bierne, N., \& David, P. (2010). Heterozygosity-fitness correlations: A time for reappraisal. Evolution, 64, 1202-1217.

Tiira, K., Laurila, A., Enberg, K., Piironen, J., Aikio, S., Ranta, E., \& Primmer, C. R. (2006). Do dominants have higher heterozygosity? Social status and genetic variation in brown trout, Salmo trutta. Behavioral Ecology and Sociobiology, 59, 657-665.

Tomiałojć, L., \& Stawarczyk, T. (2003). The avifauna of Poland. Distribution, numbers and trends. PTPP "proNatura", Wrocław (in Polish with English summary).

Townsend, S. M., \& Jamieson, I. G. (2013). Inbreeding influences within-brood heterozygosity-fitness correlations (HFCs) in an isolated passerine population. Evolution, 67, 2299-2308.

Välimäki, K., Hinten, G., \& Hanski, I. (2007). Inbreeding and competitive ability in the common shrew (Sorex araneus). Behavioral Ecology and Sociobiology, 61, 997-1005.

van de Pol, M., \& Wright, J. (2009). A simple method for distinguishing within- versus between-subject effects using mixed models. Animal Behaviour, 77, 753-758.

Van Eerden, M. R., \& Gregersen, J. (1995). Long term changes in the northwest European population of Cormorants Phalacrocorax carbo sinensis. Ardea, 83, 61-80.

Vangestel, C., Mergeay, J., Dawson, D. A., Vandomme, V., \& Lens, L. (2011). Developmental stability covaries with genome-wide and single-locus heterozygosity in house sparrows. PLOS ONE, 6, e21569.

Voegeli, B., Saladin, V., Wegmann, M., \& Richner, H. (2013). Heterozygosity is linked to the costs of immunity in nestling great tits (Parus major). Ecology and Evolution, 3, 4815-4827. 